\title{
The Design of Manipulator to Grab Wheel Hub based on Static and Dynamic Analysis
}

\author{
Jing Li, Biao Li \\ Shanghai Key Laboratory of \\ Mechanical Automation and Robotics \\ School of Mechatronics Engineering \\ and Automation, Shanghai University \\ Shanghai, China \\ \{Ianbest, 290137813\}@ shu.edu.cn
}

\author{
Hui Qian \\ Shanghai Fanuc robotics co., Ltd. \\ Shanghai, China \\ qianz@shu.edu.cn
}

\author{
Nanyan Shen \\ Shanghai Key Laboratory of \\ Mechanical Automation and Robotics \\ School of Mechatronics Engineering \\ and Automation, Shanghai University \\ Shanghai, China \\ shny@shu.edu.cn
}

\begin{abstract}
In this paper, the research object is dispatching platform of wheel hub. And the design process of palletizing manipulator for a wheel hub is introduced, which includes the structure design of manipulator, and the static and dynamic analysis to ensure structure strength and stiffness under a certain clamping force. Finally the structure of manipulator has been optimized for lightweight to ensure the palletizing manipulator meet the design requirements in every respect. In view of the design requirements of manipulator, the design steps and design ideas are provided in this article, which provided technical support for the promotion and application of robot manipulator in modern industrial manufacturing.
\end{abstract}

Keywords-wheel hub; manipulator design; palletizing; static analysis; dynamic analysis

\section{INTRODUCTION}

With the intensification of market competition, the product update cycle is shorter and shorter, and corporate demand for new technologies is more urgent. Under such a background, robotic palletizing technology has been rapid development [1]. Palletizing robot technology has great potential to solve labor shortages, improve labor productivity, reduce production cost, reduce the labor intensity of workers, and improve the production environment. Manipulator is an important part of palletizing robot [2]. Excellent palletizing technology can significantly reduce the product manufacturing cycle and strengthen the competitiveness of enterprises. It is great significance to the integral working performances of palletizing robot that performance, reliability, structure, quality and dimensions of the palletizing manipulator [3]. The function of manipulator is to complete workpiece take put movement within the specified time and the fixed path after manipulator receive signals to grab the workpiece. In order to guarantee the reliability of grabbing the workpiece in the process of work, manipulator must have a certain grab motion range, reliable positioning of workpiece in manipulator, proper clamping force, and so on. Therefore it is necessary to analysis the static and dynamic characteristics to meet the design demand of manipulator. According to different application requirements, various types of robot manipulator are designed [4] [5]. Ansys is general software to analysis the static and dynamic structure, which include stress and strain analysis, modal analysis, and so on [6]. It has significant role for designer to determine whether a manipulator meet the requirements of strength and performance.

In this article, firstly the project environment and the manipulator design demands are provided. Then according the size and shape of wheel hub, the $3 \mathrm{~d}$ model of manipulator is drawn, and the drive mechanism and drive element are selected. Finally the static and dynamic structure is analyzed by ansys software. The analyses results show that the manipulator design meet the various requirements of the properties and strength.

\section{MANIPULATOR DESIGN}

\section{A. Project background and Design requirements}

In the project of dispatching platform, the manipulator need grab three workpieces, which are car wheel hubs, support plate and diaphragm. Car wheel hub material object is shown in Figure 1(a). Wheel hub size is $15-19$ inches and diameter range is $380 \mathrm{~mm}$ to $550 \mathrm{~mm}$, among them, the maximum quality of single wheel hub is not exceed $30 \mathrm{~kg}$.

The $3 \mathrm{~d}$ model of support plate is shown in Figure 1(b). Support plate used to support a heap of wheel hub and the size is $1360 \mathrm{~mm} * 1800 \mathrm{~mm}$. It is benefit for operation workers to reserve gate location for forklift truck that includes three openings for manipulator.

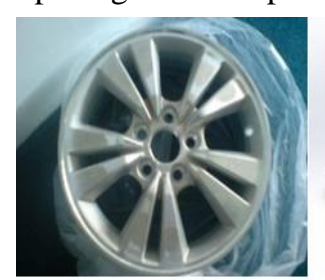

(a)

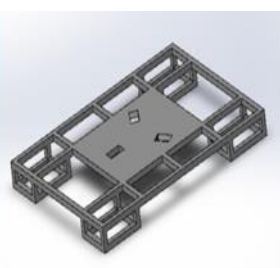

(b)

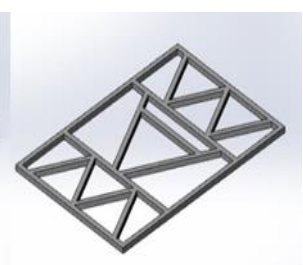

(c)
Fig. 1. The 3d model of wheel hub, support plate, and diaphragm.

The $3 \mathrm{~d}$ model of diaphragm is shown in Figure 1(c). Diaphragm size is $1360 \mathrm{~mm} * 1800 \mathrm{~mm} * 40 \mathrm{~m}$, which is used to isolate the layers of the wheel hub. Diaphragm has profile modeling position to ensure wheel hub is not move under slight 
vibration. Diaphragm made by $40 \mathrm{~mm}$ square pipe welded together as a skeleton and the manipulator can grab the diaphragm from the middle of the triangle.

The Floorplan picture of the production line is shown in Figure 2. Every time the robot palletizing and stacking a hub to maintain production balance of production line. When the upstream of production line is overcapacity, production management systems send instructions to the dispatch platform to perform palletizing, then robot will grab the wheel hub from grasp area to storage area. When the downstream of production line is overcapacity, production management systems send instructions to the dispatch platform to perform Unstacking, then robot will grab the wheel hub from storage area to place area.

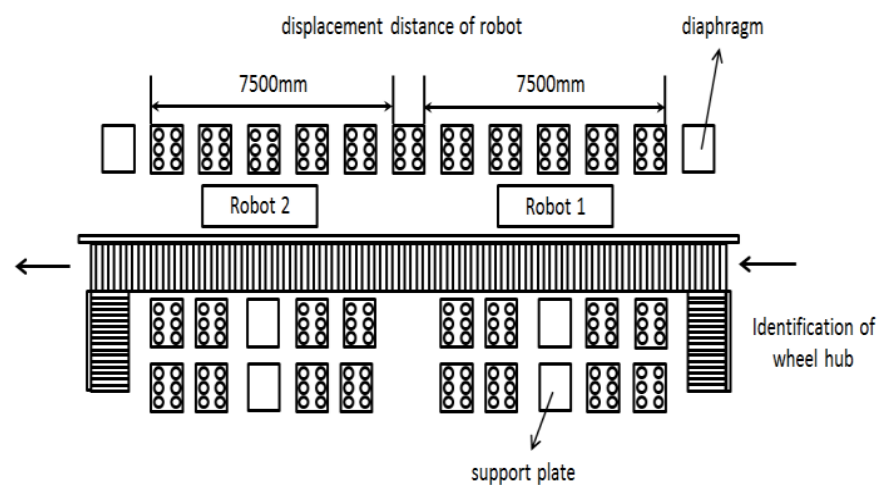

Fig. 2. The Floorplan picture of the production line.

The Figure 2 shows that two robots in production line are to keep the production balance, and the maximum movement distance of robot is $7500 \mathrm{~mm}$. It is noteworthy that when the robot speed run on the slide is $2 \mathrm{~m} / \mathrm{s}$, the design of manipulator needs to maintain its strength and stiffness under the sufficient clamping force to grab the wheel hub.

\section{B. The selection of drive mechanism and drive element}

In genera there are four drive mechanism of manipulator, which includes hydraulic drive, pneumatic drive, electric drive and mechanical drive. First, due to the limitations of mechanical drive applications, therefore it is not considered. Then although the hydraulic drive has a great ability to grab and the hydraulic drive correspond the demand of performance, but hydraulic components require high precision manufacturing and sealing performance, otherwise the oil spill would pollute the environment, so this design not use hydraulic drive. The pneumatic drive is difficult to control the speed, and its capacity of grab is low, therefore it also be excluded. Electric drive is the most kind of drive in manipulator application. The characteristic of electric drive are power supply convenient, fast response, the large driving force and easy signal detection, transmission, processing. Finally the electric drive of manipulator is selected in this scheme design.

Drive motor generally use stepper motor or servo motor as the main drive. Since the motor speed is high, usually the reduction mechanism is adapted. Compared with the stepper motor, servo motor using closed-loop control and the motor encoder feedback signal is sampled directly, which the phenomenon of lost step and overshoot does not appear and the control performance more reliable. The acceleration performance of servo motor is better and response time of servo motor is shorter, which can reduce production rhythm. Therefore servo motor is selected as the driving element of manipulator.

\section{Transmission system}

In order to intuitively analysis and calculation force of manipulator, the transmission structure and force analysis diagram of singer finger is show in Figure 3.

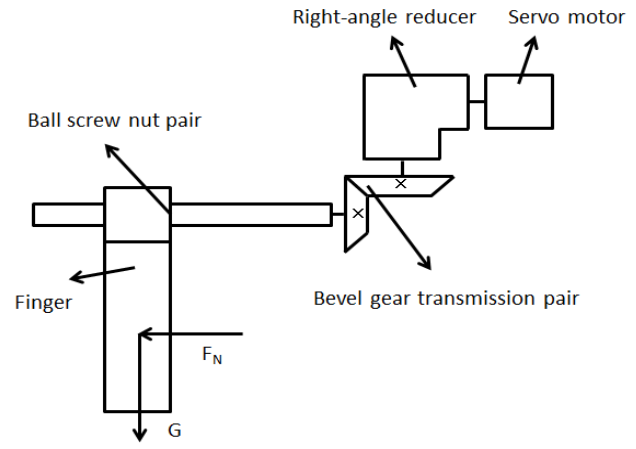

Fig. 3. The transmission structure and force analysis diagram of singer finger.

The figure 3 shows that the manipulator finger is the main load bearing parts under the effect of two forces. Among them, is the clamping force, $\mathrm{G}$ is the reaction force to balance gravity of wheel. Because the manipulator has three fingers, the value of $\mathrm{G}$ is a third of the wheel weight.

The transmission structure can divided into three parts, which includes ball screw nut pair; bevel gear transmission pair; right-angle reducer and servo motor. According the input conditions the calculation results of three parts as shown below.

\section{1) Input conditions}

The weight of singer wheel hub:

$$
G=30 \mathrm{~kg} \times 9.8 \mathrm{~N} / \mathrm{kg}=294 \mathrm{~N}
$$

The clamping force:

$$
F_{N}=2484 N
$$

2) Ball screw nut pair

The length of screw shaft:

$$
L=300 \mathrm{~mm}
$$

The diameter of screw shaft:

Lead:

$$
d=8 \mathrm{~mm}
$$

$$
P h=10 \mathrm{~mm}
$$

\section{3) Bevel gear transmission pair}

Gear modulus:

Number of teeth: 


$$
z_{1}=50, z_{2}=23
$$

Pressure angle:

$$
\alpha=20^{\circ}
$$

Cone angle:

$$
\delta_{1}=65.298^{\circ}, \delta_{2}=24.702^{\circ}
$$

Bar width:

$$
b_{1}=b_{2}=9 \mathrm{~mm}
$$

4) Right-angle reducer and servo motor

Reduction ratio:

$$
i=20
$$

The motor rated speed:

Motor power:

$$
n=3000 r / \min
$$

$$
P=31 \mathrm{~W}
$$

\section{D. tructure design of manipulator}

Due to the wheel hub is circular workpiece, the three jaws chuck of machine tool could as a reference for this manipulator structure. In order to realize the lightweight design, the manipulator select three fingers and one servo motor. The servo motor transfer torque to drive the finger movement and it can realize the synchronous clamp of three fingers. The design using three bevel gears rotations replace the rotation of small bevel gear and big bevel gear in the middle of three fingers chuck. The transmission way of thread and finger on the plan of big bevel gear is replaced by three pairs of ball screw nut pair to realize the linear motion of three fingers of manipulator.

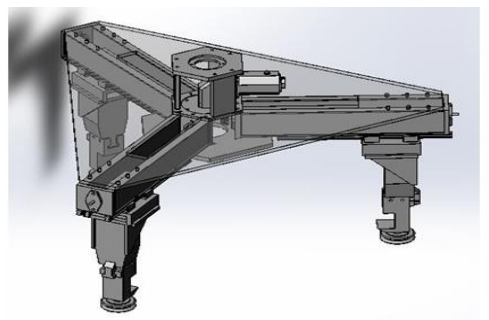

Fig. 4. The $3 \mathrm{~d}$ model of design manipulator.

Besides, additional designing for manipulator is needed to grab the wheel hub, support plate and diaphragm. The clamping wheel is installed below each finger to grab wheel hub, designing a groove in each fingers to support the support plate and diaphragm, and the force sensor installed in manipulator is used to determine the size of the force. The manipulator structure diagram is shown in figure 4.

\section{STATIC ANALYSIS}

The manipulator is the key part of the wheel hub dispatching platform, so it is the necessary conditions to enhances the working efficiency that design the superior performance manipulator. It is necessary to static analysis the manipulator used ANSYS finite element method through the $3 \mathrm{~d}$ models, which can determine the structure and deformation of the manipulator and ensure the static stiffness of manipulator in work. Thus make the manipulator to achieve the expected design requirements. There are two main aspects inspection of manipulator. One is the size of stress of manipulator. Too much stress will cause serious consequences such as manipulator break distortion, so calculating the stress is needed to ensure the stress is low than the limit stress. The other one is the size of strain caused by manipulator, because too much strain will cause the deformation of manipulator, which affect work performance.

\section{A. Select materials of manipulator}

When select materials of manipulator, a variety of factors are taken into account includes stiffness, weight, strength, flexibility, shock resistance and so on. Compared to other materials, the advantages of structural steel is high strength, big modulus of elasticity, big resistance to deformation ability. And it is the most widely used material. Therefore this manipulator material selects the structural steel, which the elastic modulus is $1.67 \mathrm{E}+11 \mathrm{~Pa}$, Poisson's ratio is 0.3 , and the density is $7850 \mathrm{~kg} / \mathrm{m}^{3}$.

\section{B. The setup of load and constraint condition}

The finger is the main part to load bearing which includes the clamp force and the friction equilibrium with wheel hub gravity. Manipulator is directly connected to the top of the robot, so it can be set fixed. According the mass of wheel hubs add the loads, the manipulator model after add the boundary conditions is show in Figure 5 in ANSYS software.

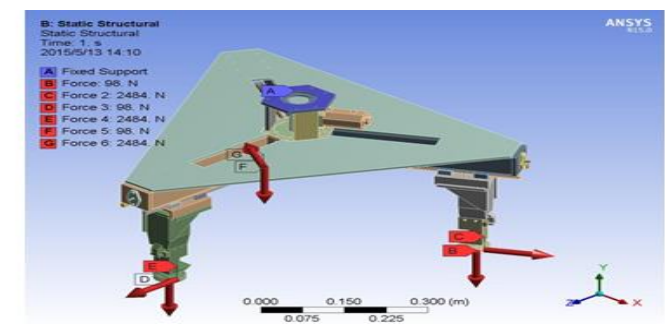

Fig. 5. The manipulator model after add the boundary conditions.

\section{Mesh generation}

Meshing generation is an important part of a finite element model and many issues that need to be considered. Meshing generation is an independent work in ANSYS Workbench platform. It can provide the corresponding grid file to different ANSYS solvers and the quality of mesh generation will directly relate to the accuracy and speed of solving solved. The model of mesh generation is show in Figure 6.

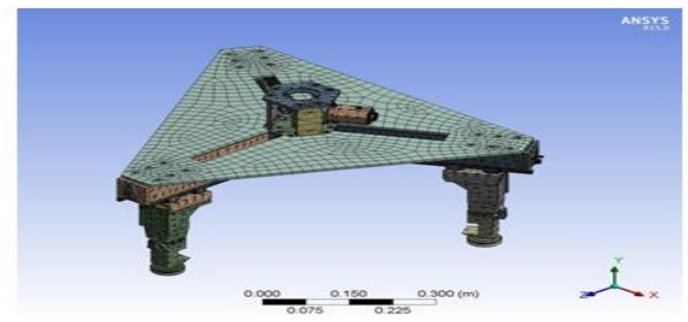

Fig. 6. The manipulator model of mesh generation. 


\section{Analysis and Conclusions}

Calculating the manipulator model by workbench and the nephogram of stress and strain is show in Figure 7 when the manipulator grabs the $30 \mathrm{~kg}$ wheel hub.

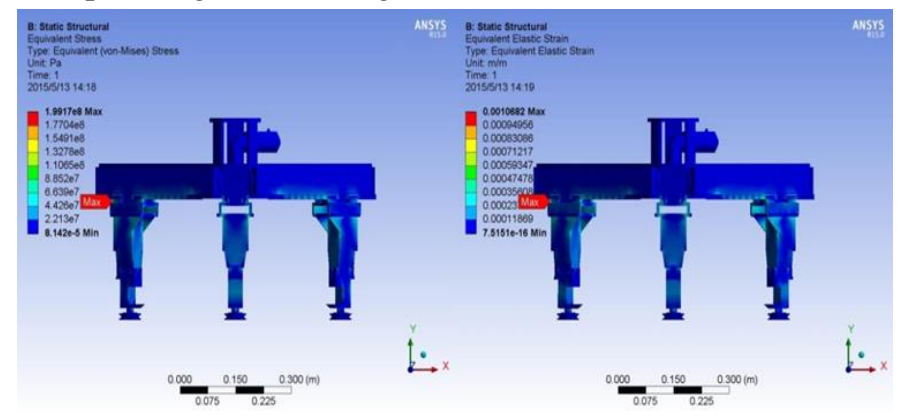

Fig. 7. The nephogram of stress and strain.

According the nephogram of stress, the local high stress area is appear in the connection part of finger and Ball screw nut pair, the maximum stress is $199 \mathrm{MPa}$. Manipulator consists of structural steel, the yield stress is $250 \mathrm{Mpa}$ and the limit stress is 460Mpa. The maximum stress value is less than permissible value of material, which shows that manipulator has good stability. Except a few connections appear the phenomenon of stress concentration, stress is mall in most regions. Therefore the strength of the manipulator meets the design requirements.

According the nephogram of strain, the maximum strain is 0.001 when the manipulator under maximum load, which also in the connection part of finger and Ball screw nut pair. The elastic deformation within the allowable range and the static stiffness of the manipulator also meets the design requirements.

\section{DYNAMIC ANALYSIS}

During operation of the manipulator, the dynamic load is existed. The vibration and response under dynamic load have a great influence on the structure and performance of the manipulator. In order to ensure the synchronization clamping accuracy of manipulator three fingers and reduce the influence of vibration, it is necessary to dynamic analysis for manipulator. The dynamic analysis includes modal analysis and transient kinetic analysis, namely the inherent vibration characteristics analysis and response characteristics analysis.

\section{A. Modal analysis}

Modal analysis is a modern method to study the structural dynamic characteristics, which is the application of system identification method in the field of engineering vibration. Modal is the natural vibration characteristics of mechanical structure, each mode has a specific natural frequencies, damping ratios and mode shapes [7].

The main work of modal analysis in this article is to compare the natural frequency of structure with the external excitation frequency then determine whether resonance occurs after the modal parameters are obtained. Manipulator of this article subject to two major external excitation, which includes the forced vibration caused by the motor and the self-excited caused by the reciprocation of robot itself.

\section{1) The calculation of external excitation}

The servo motor of manipulator is provided by FANUC, the motor rated is speed $3000 \mathrm{r} / \mathrm{min}$. So the frequency of the motor can be drawn:

$$
f=\frac{2 \pi n}{60}=\frac{2 \times \pi \times 3000}{60}=314.16 \mathrm{~Hz}
$$

In the project of dispatching platform, the maximum distance of robot is $7500 \mathrm{~mm}$, and the maximum speed of robot is $2 \mathrm{~m} / \mathrm{s}$. So the motion cycle of the robot can be drawn:

$$
t=\frac{S}{V}=2 \times \frac{7500 \times 10^{-3}}{2}=7.5 \mathrm{~s}
$$

The frequency can be drawn:

$$
f=\frac{1}{t}=\frac{1}{7.5}=0.13 \mathrm{~Hz}
$$

\section{2) Solution of modal analysis}

In the structural vibration, the distribution of low order modes and high order modes is exponential relationship. The energy of high order modes is too low and it has little effect on the entire structure. Therefore this article only needs to analyze the load frequency close to the natural frequency modes. The first six natural frequencies and the first six modal of manipulator are obtained by modal analysis of ANSYS. As the Figure 8 shows:

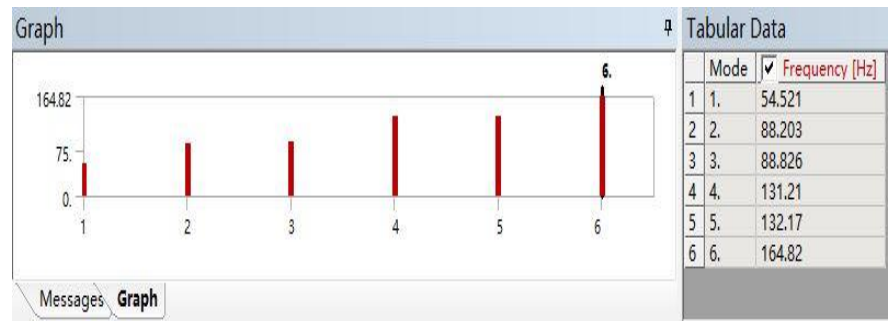

Fig. 8. The first six natural frequencies and modal of manipulator.

The figure 8 shows that whether the motor frequency of $314.16 \mathrm{~Hz}$ or the robot reciprocating frequency of $0.13 \mathrm{~Hz}$, which are far with the first six modal frequencies, so the vibration phenomenon of manipulator is not existed when the high-speed movement of the robot. In addition, the minimum frequency of the manipulator is higher than $20 \mathrm{~Hz}$, which not belong to infrasound. And it achieves the requirement to reduce noise pollution. Therefore the manipulator structure has reasonable dynamic performance.

\section{B. Transient dynamic analysis}

In static analysis, this paper introduces the distribution of stress and strain of manipulator under static load, which is a preliminary reference of manipulator design. In order to fully reflect the dynamic behavior of manipulator in the actual working, it is necessary to consider the distribution of dynamic stress and strain under dynamic loads. 
It is the key of dynamic force analysis that manipulator shock and vibration when manipulator grab the wheel hub off the ground rise to specified height. And this case is the object for transient dynamics research. Transient dynamic analysis is to analysis structure dynamic response under dynamic load time history in the time domain. The initial conditions include initial velocity, centralized mass, initial stress, initial strain, and so on. Boundary conditions include a variety of load, displacement, velocity and acceleration.

The process that manipulator grabs the wheel hub off the ground rise to specified height is divided into three stages: accelerate, uniform motion and deceleration. The accelerate time is $0.3 \mathrm{~s}$, the uniform motion time is $0.7 \mathrm{~s}$, the deceleration time is $0.3 \mathrm{~s}$. The total movement time is $1.3 \mathrm{~s}$ and the total displacement is $1.2 \mathrm{~m}$. So the speed displacement equation can be drawn:

$$
S=\frac{1}{2} a t_{1}^{2}+v t_{2}+\frac{1}{2} a t_{3}^{2}
$$

Where $S=1.2 \mathrm{~m}, t_{1}=0.3 \mathrm{~s}, \mathrm{~V}=a t_{1}, t_{2}=0.7 \mathrm{~s}$, $t_{3}=0.3 \mathrm{~s}$.

The acceleration of a can be calculated:

$$
a=4 m / s^{2} \text {. }
$$

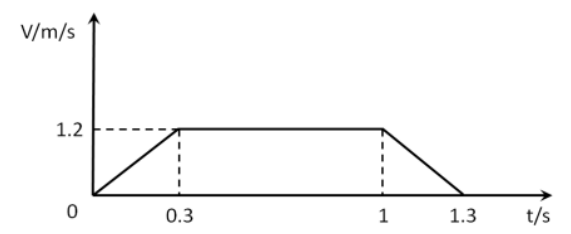

Fig. 9. The Speed - time diagram.

The Speed - time diagram is shown in Figure 9.

The force analysis diagram of manipulator is shown in Figure 10 , the manipulator mass is $50.55 \mathrm{~kg}$, the wheel hub mass is $30 \mathrm{~kg}$.

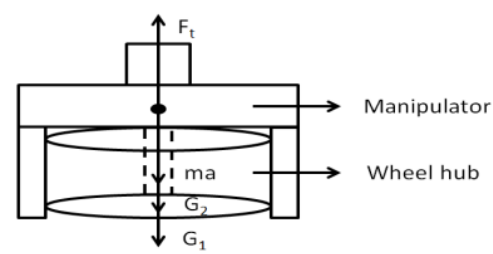

Fig. 10. The force analysis diagram of manipulator.
Where $G_{1}$ represent the gravity of the manipulator, $G_{2}$ represent the gravity of the wheel hub.

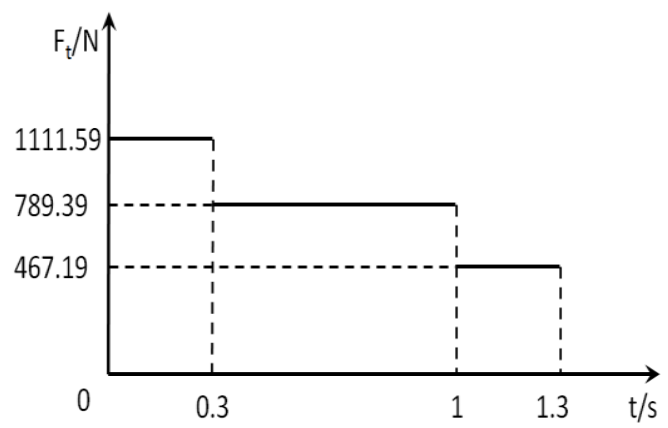

Fig. 11. The force of maniputator in each stage.

In the accelerate stage the manipulator has the maximum tension, and the force in each stage is shown in Figure 11 that the force - time diagram.

\section{ACKNOWLEDGMENT}

The design scheme was conducted with the help of FANUC Company that is dutifully acknowledged. This paper supported by project of Shanghai Municipal Commission of Economy and Informatization. The project number is CXY2016007.

\section{REFERENCES}

[1] Hemmingson E. Palletizing robots for the consumer goods industry[J]. Industrial Robot: An International Journal, 1998, 25(6): 384-388.

[2] LI X, LIU J. Research and Application Situation, Problems and Solutions of Palletizing Robots [J]. Packaging Engineering, 2011, 3: 029.

[3] Khatib O, Burdick J. Optimization of dynamics in manipulator design: The operational space formulation[J]. INT. J. ROBOTICS AUTOM., 1987, 2(2): 90-98.

[4] Causey G C, Quinn R D. Gripper design guidelines for modular manufacturing[C]//Robotics and Automation, 1998. Proceedings. 1998 IEEE International Conference on. IEEE, 1998, 2: 1453-1458.

[5] Kolluru R, Valavanis K P, Smith S S, et al. Design fundamentals of a reconfigurable robotic gripper system[J]. IEEE Transactions on Systems, Man, and Cybernetics-Part A: Systems and Humans, 2000, 30(2): 181187.

[6] Nakasone Y, Yoshimoto S, Stolarski T A. Engineering analysis with ANSYS software[J]. 2006.

[7] Li Y F, Shi G T. The modal analysis based on ANSYS of low-pressure rotor-bearing system for 600MW stream turbine[J]. Machinery Design \& Manufacture, 2007, 2(2): 71-72. 